\title{
PERANAN PENGAWAS SEKOLAH DALAM MENINGKATKAN MUTU PENDIDIKAN SDN DI KECAMATAN RUMBIO JAYA
}

\author{
Badani $^{1}$ \\ M. Nur Mustafa ${ }^{2}$ \\ Hasnah Faizah $\mathbf{A R}^{2}$ \\ ${ }^{1}$ Post Graduate Student of Riau University \\ ${ }^{2}$ Lecturer of Education Management Study Programme PPs University of Riau
}

\begin{abstract}
The purpose of this paper is to know the role of school supervisor in inspecting, Advising, Monitoring, Reporting, Coordnating (Coordinating), Performing Leadership (in leading and performing the five main tasks), in improve the quality of education as in SDN. And the factors causing the gap and the effort to eliminate the gap factors in the implementation of the role of school supervision in improving the quality of education in the SDN. Efforts to eliminate the causes of gaps in the implementation of school supervisors in improving the quality of education in SDN. To study it the authors use a qualitative approach with mixed data collection techniques or mix method. It is expected that school supervisors can perform their role in the effort to improve the quality of education in the schools they supervise.
\end{abstract}

Key words: School Supervisor, Improving the Quality of Education

\begin{abstract}
Abstrak: Tujuan dari penulisan ini untuk mengetahui peranan pengawas sekolah dalam inspecting (mensupervisi), Advising (member nasehat), Monitoring (memantau), Reporting (membuat laporan), Coordnating (mengkoordinir), Performing Leadership (memimpin dan melaksanakan kelima tugas pokok tersebut), dalam meningkatkan mutu pendidikan seperti di SDN. Dan faktor-faktor sebab terjadinya kesenjangan dan upaya menghilangkan faktor-faktor kesenjangan dalam pelaksanaan peranan pengawasan sekolah dalam meningkatkan mutu pendidikan di SDN. Upaya-upaya menghilangkan faktor-faktor sebab terjadinya kesenjangan dalam pelaksanaan pengawas sekolah dalam meningkatkan mutu pendidikan di SDN. Untuk mengkaji hal tersebut penulis menggunakan pendekatan kualitatif dengan teknik pengumpulan data campuran atau mix method. Diharapkan pengawas sekolah dapat menjalankan peranannya dalam upayan meningkatkan mutu pendidikan di sekolah yang diawasinya.
\end{abstract}

Kata Kunci: Pengawas Sekolah, Meningkatkan Mutu Pendidikan

\section{PENDAHULUAN}

Dalam upaya meningkatkan mutu pendidikan seperti di sekolah SDN, perlu dilakukan secara integratif kerjasama kepala sekolah, guru dan pengawas sekolah. Dalam pelaksanaannya kepala sekolah berperan sebagai pimpinan, guru berperan tenaga pengajar dan pengawas atau suverpisi berperan sebagai pembina dan penilai.Menurut Rohmat (2012 : 97), bahwa pengawas sekolah berperan sebagai superintendent, guru memiliki mindset dan thintank bagi pengawas. Guru merupakan komponen sumber daya yang keberadaanya sangat menentukan, dalam meningkatkan mutu keluaran. Oleh karena itu perlu guru yang profesional memerlukan sistem pembinaan karier yang baik, tersistem, dan berkelanjutan (Suyanto, 2001).

Berdasarkan PP No. 19 Tahun 2005 tentang standar mutu pendidikan, peranan pengawas satuan pendidikan/sekolah sangat penting dalam meningkatkan mutu pendidikan pada satuan pendidikan binaannya. Oleh sebab itu, pembinaan pengawas agar dapat melaksanakan tugas kepengawasan akademik dan manajerial mutlak diperlukan. Karena menurut Nana Sudjana (2011:28) peran dan tugas pokok Pengawas Sekolah adalah melaksanakan pengawasan akademik dan pengawasan manajerial pada satuan pendidikan.Yang dimaksud dengan supervisi akademik meliputi aspek-aspek pelaksanaan proses 


\section{JURNAL}

MANAJEMEN PENDIDIKAN

PENELITIAN KUALITATIF
Vol. 4 No.1 Maret 2020: pp.19-26

p-ISSN: 2502-9487

pembelajaran. Itulah sebabnya supervise manajerial sasarannya adalah kepala sekolah dan staf sekolah lainnya, sedangkan supervisi akademik sasarannya adalah guru.

Tugas Pokok dan Fungsi Pengawas Sekolah berdasarkan Peraturan Menteri Negara Pendayagunaan Aparatur Negara Dan Reformasi Birokrasi Nomor: 21 Tahun 2010 Pasal 5 tentang tugas Pokok Pengawas Sekolah adalah melaksanakan tugas pengawasan akademik dan manajerial pada satuan pendidikan yang meliputi penyusunan program pengawasan, pelaksanaan pembinaan, pemantauan pelaksanaan 8 (delapan) Standar Nasional Pendidikan, penilaian, pembimbingan dan pelatihan professional guru, evaluasi hasil pelaksanaan program pengawsan, dan pelaksanaan tugas pengawasan di daerah khusus. Sejak itulah pengawas sekolah bertugas sebagai penilai dan pembina bidang teknik edukatif dan teknik adminsitratif di sekolah yang menjadi tanggung jawabnya.

Secara tegas dikatakan dalam Keputusan Menpan No.21 Tahun 2010, BAB I Pasal 1 Ayat 2 sebagai berikut, "Pengawas sekolah adalah Pegawai Negeri Sipil yang diberi tugas, tanggungjawab, dan wewenang secara penuh oleh pejabat yang berwenang untuk melaksanakan kegiatan pengawasan akademik dan manajerial pada satuan pendidikan."

Inti tugas pokok dan fungsi pengawas sekolah adalah menilai dan membina. Subjek yang dinilai adalah teknis pendidikan dan administrasi pendidikan. Penilaian menurut PP 19/2005, bab I, pasal 1, ayat (17) adalah seperti betikut ini, "Penilaian adalah proses pengumpulan dan pengolahan informasi untuk mengukur pencapaian hasil belajar peserta didik." Sedangkan Kepmenpan No. 118/1996, bab I, pasal 1, ayat (8) menyatakan, "Penilaian adalah penentuan derajat kualitas berdasarkan kriteria (tolok ukur) yang ditetapkan terhadap penyelenggaraan pendidikan di sekolah."

Fakta di lapangan menunjukkan bahwa pengawas sekolah belum maksimal dalam melaksanakan tugas dalam mengawas. Meskipun dalam rancangan secara teoritik sudah ada pihak yang diharapkan dapat melaksanakan melaksanakan supervisi terhadap guru, namun belum terlaksana secara efektif. Buktinya berdasarkan pengalaman seorang guru yang sudah bertugas 5 tahun menjadi guru di Kecamatan Rumbio Jaya Kabupaten Kampar, pengawas sekolah mengadakan kunjungan /datang ke sekolah-sekolah guna melaksanakan salah satu tugas sebagai pengawas sekolah yaitu mengadakan supervisi dan monitoring hanya pada waktu-waktu tertentu. Supervisi hanya dilakukan setahun sekali, itupun terfokus pada supervisi administrasi baik yang harus dibuat guru maupun kepala sekolah. Dari kenyataan yang ada, supervisi yang telah diadakan oleh pengawas sekolah belum berarti terhadap peningkatan kualitas pembelajaran sebagi upaya peningkatan mutu pendidikan. Perhatian supervisi hendaknya tertuju pada keberhasilan siswa dalam memperoleh ilmu dan keterampilan di sekolah. Oleh karena siswalah yang menjadi pusat perhatian dari segala upaya pendidikan, berarti bahwa supervisi sudah mengarah pada subjeknya.

Pengalaman dilapangan menunjukan bahwa dari serangkaian kegiatan supervisi maupun monitoring yang dilaksanakan oleh pengawas sekolah di kecamatan Rumbio Jaya belum memperoleh hasil yang signifikan dalam meningkatkan mutu pendidikan. Keberhasilan sasaran supervisi yang meliputu tiga domain, yaitu: memperbaiki pengajaran, pengembangan kurikulum, dan pengembangan staf. Terbukti dari kondisi yang ada sekarang ini, guru sebagaian besar masuk dalam kategori "orangorang yang bersifat rutin." Mereka pagi berangkat, siang pulang tanpa beban bahwa sesungguhnya guru memiliki beban yang berat tapi muliya yakni mengantarkan putra putri bangsa supaya menjadi manusia yang bermutu atau berkualitas, sesuai yang diamanatkan dalam UU RI No.20 Tahun 2003.

Suharsimi Arikunto (2007), memberikan alasan yang utama bertumpu pada dua hal, yaitu: (1) beban kerja pengawas sekolah dan kepala sekolah terlalu berat dan (2) latar belakang pendidikan mereka kurang sesuai dengan bidang studi yang disupervisi. Mengingat banyaknya bidang studi yang yang diajarkan oleh guru-guru di sekolah, terasa mengalami kesulitan untuk mempertemukan keduanya. Oleh karena itu, perlu dicari alternatif cara yang lebih tepat bagi kondisi lapangan, baik langsung maupun tidak langsung, yang mengarah pada pencapaian tujuan pembelajaran yang optimal guna peningkatan mutu pendidikan.

\section{METODOLOGI PENELITIAN}

Penelitian ini termasuk jenis penelitian kualitatif. Untuk mengkaji hal tersebut penulis menggunakan pendekatan kualitatif dengan teknik pengumpulan data campuran atau mix method. Diharapkan pengawas sekolah dapat menjalankan peranannya dalam upayan meningkatkan mutu pendidikan di sekolah yang diawasinya. 


\section{HASIL DAN PEMBAHASAN}

\section{Pengertian Peranan}

Istilah peran mengalami perubahan seiring dengan perkembangan studi peran itu sendiri. Istilah peran dalam "Kamus Besar Bahasa Indonesia" mempunyai arti pemain sandiwara (film), tukang lawak pada permainan makyong, perangkat tingkah yang diharapkan dimiliki oleh seorang yang berkedudukan di masyarakat (Kamus Besar Bahasa Indonesia, 2005). Berdasarkan SK Menpan No. 21 Tahun 2010 tentang jabatan fungsional pengawas sekolah dan angka kreditnya dalam Bab 1 pasal 1 ayat 3 dan 4, dapat dinyatakan tentang tugas pokok dan tanggung jawab pengawas sekolah yaitu (a) melaksanakan pengawasan penyelenggaraan pendidikan di sekolah sesuai dengan satuan seperti Sekolah Dasar (SD); (b) kegiatan pengawasan adalah kegiatan pengawas sekolah dalam menyusun program pengawas, melaksanakan program pengawasan, evaluasi hasil pelaksanaan program, dan melaksanakan pembimbingan dan pelatihan profesional guru.Dengan demikian, peranan merupakan aspek yang dinamis dari kedudukan (status). Apabila seseorang melakukan hak dan kewajibannya sesuai dengan keudukannya, maka dia menjalankan peranannya. Peranan ini dianalisis melalui tiga pendekatan yaitu: (a) ketentuan peranan adalah pernyataan formal dan terbuka tentang perilaku yang yang harus ditampilkan oleh seorang dalam membawa perananya; (b) gambaran peranan adalah gambaran tentang perilaku secara aktual ditampilkan seseorang dalam membawa perannya; (c) harapan peranan adalah harapan orang-orang terhadap perilaku yang ditampilkan seseorang dalam membawakan perananya, pada tugas pengawas sekolah (Soekanto Soejono, 1990).

\section{Konsep Fungsi Pengawasan}

Untuk melaksanakan tugas pokok, maka pengawas sekolah melaksanakan fungsi supervisi, baik fungsi akademik maupun supervisi manajerial, sebagaimana yang sudah dijelaskan di atas. Supervisi akademik adalah fungsi supervisi yang berkaitan dengan aspek pembinaan dan pengembangan kemampuan profesional gueu dalam meningkatkan mutu pembelajaran dan bimbingan di sekolah. Dalam melaksanakan fungsi supervisi akademik, seorang pengawas hendak berperan seperti: (a) mitra guru dalam meningkatkan mutu proses dan hasil pembelajaran dan bimbingan di sekolah binaan; (b) inovator dan pelopor dalam mengembangkan inovasi pembelajaran dan bimbingan di sekolah binaannya; (c) konsultan pendidikan di sekolah binaannya; (d) konselor bagi kepala sekolah, guru dan seluruh staf sekolah; (e) motivator untuk meninhgkatkan kinerja semua staf sekolah ( Joko Budi Santoso, 2011: 29)

Supervisi sekolah manajerial adalah funsi supervisi yang berkenaan dengan aspek pengelolaan sekolah yang terkait langsung dengan peningkatan efi siensi dan efektivitas sekolah yang mencakup hal seperti perencanaan, koordinasi, pelaksanaan, penilaian, pengembangan kompetensi SDM kependidikan dan sumberdaya lainnya. Sasaran supervisi adalah membantu kepala sekolah dan staf sekolah lainnya dalam mengelola administrasi pendidikan seperti: administrasi kurikulum, administrasi keuangan, administrasi sarana prasarana, administrasi personal atau ketenagaan, administrasi kesiswaan, adminis hubungan sekolah dan masyarakat, administrasi budaya dan linghkungan sekolah, serta aspek-aspek administrasi lainnya dalam rangka meningkatkan mutu pendidikan.

Selanjutnya, ketika melaksanakan fungsi supervisi manajerial, seorang pengawas berperan sebagai (a) kolaborator dan negosiator dalam proses perencanaa, koordinasi, pengembangan manajemen sekolah; (b) asesor dalam mengidentifikasi kelemahan dan menganalisis potensi sekolah binaan; (c) pusat informasi pengembangan mutu pendidikan di sekolah binaannya; (d) evaluator terhadap pemaknaan hasil pengawasan (Joko Budi Santoso, 2011: 30)

Dengan demikian dapat dikatakan bahwa fungsi pengawas sekolah adalah orang yang melaksanakan kegiatan suvervisi akademik, dan supervisi manajerial, yang dapat dilihat secara nyata melalui peningkatan mutu pendidikan di sekolah tempat dia mengawas atau mensuvervisi.

\section{Pengawas Sekolah}

Mutu pendidikan dalam konteks ini adalah mutu proses pembelajaran dan hasil belajar yang dapat dilihat dengan Ujian Nasional. Tentang Standar Nasional Pendidikan, Standar proses adalah standar naisonal pendidikan yang berkaitan dengan pelaksanaan pembelajaran pada satu satuan pendidikan untuk mencapai standar kompetensi lulusan. Standar kompetensi lulusan ditegaskan pada kualifikasi kemampuan lulusan yang mencakup sikap, pengetahuan, dan keterampilan (Anas Rupaedi, 2012: 23) 


\section{JURNAL}

MANAJEMEN PENDIDIKAN

PENELITIAN KUALITATIF
Vol. 4 No.1 Maret 2020: pp.19-26

p-ISSN: 2502-9487

Proses pembelajaran pada satuan pendidikan diselenggarakan secara interaktif, inspiratif, menyenangkan, menantang, memotivasi perserta didik untuk berpartisipasi aktif, serta memberikan ruang yang cukup bagi prakarsa, kretivitas, dan kemandirian sesuai dengan bakat, minat, dan perkembangan fisik serta psikologis peserta didik.Selain ketentuan sebagaimana yang dimaksud Setiap satuan pendidikan melakukan perencanaan proses pembelajaran, pelaksanaan proses pembelajaran, penilaian proses pembelajaran, dan pengawasan proses pembelajaran untuk terlaksananya proses pembelajaran yang efektif dan efisien.

Jadi, mutu pendidikan dalam konteks ini adalah mutu proses yang mengacu kepada standar proses dan mutu hasil yang mengacu kepada standar kompetensi lulusan. Mutu proses memiliki hubungan kausal dengan mutu hasil. Jika proses pembelajaran bermutu, tentulah standar komptensi lulusan dapat dicapai dengan bermutu pula ketika Ujian Nasional..

Dalam proses pendidikan, pengawasan atau supervisi merupakan bagian tidak terpisahkan dalam upaya peningkatan prestasi belajar dan mutu sekolah. Sahertian (2000:19) menegaskan bahwa pengawasan atau supervisi pendidikan tidak lain dari usaha memberikan layanan kepada stakeholder pendidikan, terutama kepada guru-guru, baik secara individu maupun secara kelompok dalam usaha memperbaiki kualitas proses dan hasil pembelajaran. Burhanuddin, memperjelas hakikat pengawasan pendidikan pada hakikat substansinya. Substansi hakikat pengawasan yang dimaksud menunjuk pada segenap upaya bantuan supervisor kepada stakeholder pendidikan terutama guru yang ditujukan pada perbaikan-perbaikan dan pembinaan aspek pembelajaran (Salam Burhanudin, 1996).

Indikator peningkatan mutu pendidikan di sekolah dilihat pada setiap komponen pendidikan antara lain: mutu lulusan, kualitas guru, kepala sekolah, staf sekolah (Tenaga Administrasi, Laboran dan Teknisi, Tenaga Perpustakaan), proses pembelajaran, sarana dan prasarana, pengelolaan sekolah, implementasi kurikulum, sistem penilaian dan komponen-lainnya. Ini berarti melalui pengawasan harus terlihat dampaknya terhadap kinerja sekolah dalam meningkatkan mutu pendidikannya. Itulah sebabnya kehadiran pengawas sekolah harus menjadi bagian integral dalam peningkatan mutu pendidikan, agar bersama guru, kepala sekolah dan staf sekolah lainnya berkolaborasi membina dan mengembangkan mutu pendidikan di sekolah yang bersangkutan seoptimal mungkin sesuai dengan standar yang telah ditetapkan.

Untuk mencapai standar yang sudah ditetapkan tersebut berdasarkan SK Menpan nomor 118 tahun 1996 bahwa tugas pokok dan tanggung jawab pengawas sekolah meliputi:

1. Menyusun program kerja kepengawasan untuk setiap semester dan setiap tahunnya pada sekolah yang dibinanya.

2. Melaksanakan penilaian, pengolahan dan analisis data hasil belajar/bimbingan siswa dan kemampuan guru.

3. Mengumpulkan dan mengolah data sumber daya pendidikan, proses pembelajaran/bimbingan, lingkungan sekolah yang berpengaruh terhadap perkembangan hasil belajar/bimbingan siswa.

4. Melaksanakan analisis komprehensif hasil analisis berbagai faktor sumber daya pendidikan sebagai bahan untuk melakukan inovasi sekolah.

5. Memberikan arahan, bantuan dan bimbingan kepada guru tentang proses pembelajaran/bimbingan yang bermutu untuk meningkatkan mutu proses dan hasil belajar/ bimbingan siswa.

6. Melaksanakan penilaian dan monitoring penyelenggaran pendidikan di sekolah binaannya mulai dari penerimaan siswa baru, pelaksanaan pembelajaran, pelaksanaan ujian sampai kepada pelepasan lulusan/pemberian ijazah.

7. Menyusun laporan hasil pengawasan di sekolah binaannya dan melaporkannya kepada Dinas Pendidikan, Komite Sekolah dan stakeholder lainnya.

8. Melaksanakan penilaian hasil pengawasan seluruh sekolah sebagai bahan kajian untuk menetapkan program kepengawasan semester berikutnya.

9. Memberikan bahan penilaian kepada sekolah dalam rangka akreditasi sekolah.

10. Memberikan saran dan pertimbangan kepada pihak sekolah dalam memecahkan masalah yang dihadapi sekolah berkaitan dengan penyelenggaraan pendidikan (Nana Sudjana. 2006)

Berdasarkan uraian di atas maka tugas pengawas mencakup: (1) inspecting (mensupervisi), (2) advising (memberi advis atau nasehat), (3) monitoring (memantau), (4) coordinating (mengkoordinir), (5) reporting (membuat laporan), dan (6) performing leadership dalam arti memimpin dalam melaksanakan kelima tugas pokok tersebut. 


\section{JURNAL}

MANAJEMEN PENDIDIKAN

PENELITIAN KUALITATIF
Vol. 4 No.1 Maret 2020: pp.19-26

p-ISSN: 2502-9487

Tugas pokok inspecting (mensupervisi) meliputi tugas mensupervisi kinerja kepala sekolah, kinerja guru, kinerja staf sekolah, pelaksanaan kurikulum/mata pelajaran, pelaksanaan pembelajaran, ketersediaan dan pemanfaatan sumberdaya, manajemen sekolah, dan aspek lainnya seperti: keputusan moral, pendidikan moral, kerjasama dengan masyarakat.

Tugas pokok advising (memberi advis/nasehat) meliputi advis mengenai sekolah sebagai sistem, memberi advis kepada guru tentang pembelajaran yang efektif, memberi advis kepada kepala sekolah dalam mengelola pendidikan, memberi advis kepada tim kerja dan staf sekolah dalam meningkatkan kinerja sekolah, memberi advis kepada orang tua siswa dan komite sekolah terutama dalam meningkatkan partisipasi masyarakat dalam pendidikan.

Tugas pokok monitoring/pemantauan meliputi tugas: memantau penjaminan/ standard mutu pendidikan, memantau penerimaan siswa baru, memantau proses dan hasil belajar siswa, memantau pelaksanaan ujian, memantau rapat guru dan staf sekolah, memantau hubungan sekolah dengan masyarakat, memantau data statistik kemajuan sekolah, memantau program-program pengembangan sekolah.

Tugas pokok reporting meliputi tugas: melaporkan perkembangan danhasil pengawasan kepada Kepala Dinas Pendidikan Kabupaten/Kota, Propinsi dan/atau Nasional, melaporkan perkembangan dan hasil pengawasan ke masyarakat publik, melaporkan perkembangan dan hasil pengawasan ke sekolah binaannya.

Tugas pokok coordinating meliputi tugas: mengkoordinir sumber-sumber daya sekolah baik sumber daya manusia, material, financial dll, mengkoordinir kegiatan antar sekolah, mengkoordinir kegiatan preservice dan in service training bagi Kepala Sekolah, guru dan staf sekolah lainnya, mengkoordinir personil stakeholder yang lain, mengkoordinir pelaksanaan kegiatan inovasi sekolah.

Tugas pokok performing leadership/memimpin meliputi tugas: memimpin pengembangan kualitas SDM di sekolah binaannya, memimpin pengembangan inovasi sekolah, partisipasi dalam memimpin kegiatan manajerial pendidikan di Diknas yang bersangkutan, partisipasi pada perencanaan pendidikan di kabupaten/kota, partisipasi pada seleksi calon kepala sekolah/calon pengawas, partisipasi dalam akreditasi sekolah, partisipasi dalam merekruit personal untuk proyek atau program-program khusus pengembangan mutu sekolah, partisipasi dalam mengelola konflik di sekolah dengan win-win solution dan partisipasi dalam menangani pengaduan baik dari internal sekolah maupun dari masyarakat. Itu semua dilakukan guna mewujudkan kelima tugas pokok di atas.

\section{Mutu Pendidikan}

Dalam kamus besar Bahasa Indonesia "mutu"berarti karat. Baik buruknya sesuatu, kualitas, taraf atau derajat (kepandian, kecerdasan). Pendidikan adalah perubahan mendidik jadi secara etimologi mutu pendidikan adalah kualitas perbuatan mendidik, perbuatan mendidik disini adalah interaksi antara guru dan murid dalam proses belajar mengajar di kelas. Istilah mutu menurut Sanusi Uwes (1999: 27) mengandung dua hal sifat dan taraf. Sifat merupakan suatu yang menerangkan keadaan benda sedangkan taraf menunjukkan kedudukan dalam suatu skala. Suryadi dan Tilaar menjelaskan bahwa mutu pendidikan adalah merupakan kemampuan sistem pendidikan yang diarahkan secara efektif untuk meningkatkan nilai tambah faktor input agar menghasilkan out put yang setinggi-tingginya.

Indikator keberhasilan dalam meningkatkan mutu pendidikan akan berdampaka dari berbagai aspek, yaitu: (1) Efektifitas proses pembelajaran bukan sekedar transfer pengetahuan (transfer Knowledge) atau pengingat, melainkan lebih menekankan pada internalisasi mengembangkan aspek kognitif, afektefi dan psikomotor dan kemandirian, (2) kempimimpinan kepala sekolah akan mendorong terwujudnya visi, misi, tujuan sasran melalui program yang dilaksanakan secara berencana, bertahap, kreatifitas, inovasi, efektif, mempunyai kemampuan manajerial, (3) pengelolaan tenaga kependidikan yang efektif, (4) sekolah memiliki budaya mutu, (5) sekolah memiliki team work yang kompak, cerdas dan dinamis. Karena output pendidikan merupakan hasil kolektif bukan hasil individu guna memperoleh mutu yang kompetitif, (6) sekolah memiliki kemandirian, yaitu kemampuan untuk bekerja secara maksimal dengan tidak tergantung petunjuk dari atasan dan memiliki sumber daya manusia yang potensial, (7) patitsipasi warga sekolah dan masyarakat. Keterkaitan dan keterlibatan pada sekolah harus tinggi dilandasi oleh rasa tanggunjawab melalui loyalitas dan dedikasi sebagai steakholders, (8) sekolah memiliki transparansi, (9) sekolah memiliki kemauan perubahan (management change). Perubahan adalah peningkatan bermakna positif untuk lebih baik dalam peningkatan mutu pendidikan, (10) sekolah melakukan evaluasi perbaikan yang berkelanjut dan merupakan proses penyempurnaan dalam meningkatkan mutu keseluruhan, mencakup organisasi, tanggung jawab, prosedur dan 


\section{JURNAL}

MANAJEMEN PENDIDIKAN

PENELITIAN KUALITATIF
Vol. 4 No.1 Maret 2020: pp.19-26

p-ISSN: 2502-9487

sumber daya manusia, (11) sekolah memiliki akuntabilitas sebagai tanggun jawab terhadap keberhasilan program sekolah yang telah dilaksanakan, (12) output sekolah penekanannya kepada lulusan yang mandiri dan memenuhi syarat pekerjaan (qualified) (sagala, 2010: 172).

Jadi mutu pendidikan bukanlah suatu konsep yang berdiri sendiri melainkan terkait dengan tuntunan dan kebutuhan masyarakat. Dimana kebutuhan masyarakat dan perubahan yang terjadi bergerak dinamis seiring dengan perkembangan zaman, sehingga pendidikan juga harus bisa menyeimbangi perubahan yang terjadi secara cepat, dan bisa menghasilkan lulusan yang sesuai dengan kebutuhan masyarakat.

\section{Prinsip-Prinsip Mutu Pendidikan.}

Program supervisi berprinsip kepada proses pembinaan guru yang menyediakan motivasi yang kaya bagi pertumbuhan kemampuan profesionalnya dalam mengajar. Ia menjadi bagian integral dalam upaya peningkatan mutu sekolah (Suhardan, 2010; Ruzi Rahmawati, 2012).

Untuk menetapkan kriteria pendidikan yang bermutu terdapat beberapa pendekatan yang digunakan. Menurut Hoy Fergusen yaitu: Pendekatan pencapaian tujuan, meliputi:

a. Siswa mampu menguasai keterampilan-keterampilan dasar

b. Siswa dapat meraih prestasi akademik semaksimal mungkin pada semua mata pelajaran.

c. Adanya evaluasi yang sistematis menunjukkan adanya keberhasilan (Hoy Fergusen, 2008).

Agar terwujudnya mutu pendidikan tersebut maka perlu ada prinsip-prinsip peningkatan mutu pendidikan, diantara prinsip-prinsip tersebut sebagaimana dikemukan oleh Nana Syaodih (2006: 9-11) sebagai berikut:

a.Peningkatan mutu pendidikan menuntut kepemimpinan (pengawas) professional dalam bidang pendidikan.

b. Kesulitan yang dihadapi para professional pendidikan adalah ketidakmampuan mereka dalam menghadapi "keagalan sistem" yang mencegah mereka dari pengembangan atau penerapan cara atau proses baru untukmemperbaiki mutu pendidikan yang ada.

c. Peningkatan mutu pendidikan harus melakukan loncatan-loncatan norma dan kepercayaan lama harus dirubah.

d. Uang bukan kunci utama dalam usaha peningkatan mutu.

e. Kunci utama peningkatan mutu pendidikan adalah komitmen pada perubahan.

f. Banyak professional di bidang pendidikan yang kurang memiliki pengetahuan dan keahlian dalam menyiapkan para siswa memasuki pasar yang bersifat global.

g. Program peningkatan mutu dalam bidang komersial tidak dapat dipakai secara langsung dalam pendidikan, tetapi membutuhkan penyesuaian dan penyempurnaan.

h. Salah satu komponen kunci dalam program mutu adalah sistem pengukuran.

i. Masyarakat dan manajemen pendidikan harus menjauh diri dari kebiasaan menggunakan program singkat, peningkatan mutu dapat dicapai melalui perubahan yang berkelanjutan tidak dengan programprogram singkat.

Dengan demikian dapat diketahui dan dipahami bahwa begitu pentingnya mutu pendidikan. Dan akan meningkat bila ditunjangi dari kualitas komponen-komponen tersebut dan menjalankan peranannya, mulai dari pengawas sekolah, kepala sekolah, staf, sarana prasarananya sampai siswa serta lingkungan masyarakatnya. Keseluruhan komponen tersebut harus mampu dipertanggung jawabkan, dan memiliki standar kualitas yang baik.

Faktor-Faktor Sebab Terjadinya Kesenjangan Dalam Pelaksanaan Peranan Pengawasan Sekolah Dalam Meningkatkan Mutu Pendidikan

1. Kurangnya pembinaan kemampuan profesional pengawas sekolah

2. Sumber daya yang terbatas.

3. Kurangnya respon positif kepada pengawas sekolah dibandingkan dengan guru dan kepala sekolah.

4. Peran pengawas dalam konteks peningkatan mutu pendidikan belum sejalan dengan PP No. 19 Tahun 2005 tentang standar mutu pendidikan.

5. Cara pengawas sekolah kurang baik.

6. Kurangnya pembinaan pengawas sekolah secara terpola.

7. Penempatan tugas pengawas tidak secara terpola. 
Upaya-Upaya Menghilangkan Faktor-Faktor Sebab Terjadinya Kesenjangan Dalam Pelaksanaan Pengawasan Pengawas Sekolah Dalam Meningkatkan Mutu Pendidikan di Sekolah Dasar

1. Supervisor. Dalam melaksanakan fungsi supervisi, pengawas hendaknya berperan sebagai: (a) Mitra guru dalam meningkatkan mutu proses dan hasil pembelajaran dan bimbingan di sekolah binaannya; (b) Inovator dan pelopor dalam mengembangkan inovasi pembelajaran dan bimbingan di sekolah binaannya; (c) Konsultan pendidikan di sekolah binaannya; (d) Konselor bagi kepala sekolah, guru dan seluruh staf sekolah; (e) Motivator untuk meningkatkan kinerja semua staf sekolah.

2. Advising. Dalam melaksanakan fungsi supervisi, pengawas hendaknya berperan sebagai: Pemberi arahan, bantuan dan bimbingan kepada guru tentang proses pembelajaran/bimbingan yang bermutu untuk meningkatkan mutu proses dan hasil belajar/ bimbingan siswa.

3. Monitoring. Pengawas sebagai pemantau mempunyai tiga peran, pertama sebagai pemantau perencanaan pendidikan di sekolah, kedua memantau proses pengambilan keputusan, ketiga memantau kualitas kebijakan program dan proses perencanaan pendidikan di sekolah.

4. Reporting. Peran sebagai reporting adalah melaporkan output pendidikan, melaporkan hasil ujian akhir, melaporkan angka partisipasi sekolah, melaporkan proses perencanaan pendidikan, penyusunan tehadap program sekolah yang harus dilaporkan kepada kepala dinas, masyarakat, dan sekolah itu sendiri.

5. Coordinating. Tugas mengkoordinir sumber-sumber daya sekolah baik sumber daya manusia, material, financial dll, mengkoordinir kegiatan antar sekolah, mengkoordinir kegiatan preservice dan in service training bagi Kepala Sekolah, guru dan staf sekolah lainnya, mengkoordinir personil stakeholder yang lain, mengkoordinir pelaksanaan kegiatan inovasi sekolah.

6. Performing leadership memimpin pengembangan kualitas SDM di sekolah binaannya, memimpin pengembangan inovasi sekolah, partisipasi dalam memimpin kegiatan manajerial pendidikan di Diknas yang bersangkutan, partisipasi pada perencanaan pendidikan di kabupaten/kota, partisipasi pada seleksi calon kepala sekolah/calon pengawas, partisipasi dalam akreditasi sekolah, partisipasi dalam merekrut personal untuk proyek atau program-program khusus pengembangan mutu sekolah, partisipasi dalam mengelola konflik di sekolah dengan win-win solution dan partisipasi dalam menangani pengaduan baik dari internal sekolah maupun dari masyarakat.

7. Pembinaan Pengawa secara terpola. Pembinaan pengawas satuan pendidikan atau pengawas sekolah harus dirancang dan dikembangkan secara terpola dan bersinambungan agar kemampuan profesional dan karir pengawas satuan pendidikan mendorong peningkatan kinerjanya. Pembinaan dilaksanakan oleh Direktorat Tenaga Kependidikan dan oleh Kepala Dispora Pendidikan Kota/Kabupaten dan atau Dinas Pendidikan tingkat propinsi melalui program-program yang jelas, terarah serta dievaluasi secara terencana.

8. Penempatan tugas Pengawas secara tepat. Penempatan tugas pengawas satuan pendidikan menjadi tanggung jawab Kepala Dinas Pendidikan Provinsi dan atau Kabupaten/Kota dengan mempertimbangkan tipe dan kondisi geografis letak sekolah selaras dengan bidang dan jenjang jabatan pengawas. Selanjutnya pembinaan dan pengembangan pengawas satuan pendidikan dilaksanakan secara berkelanjutan agar kemampuan profesional serta karirnya sebagai pengawas satuan pendidikan meningkat sejalan dengan prestasi yang dicapainya. Dengan kata lain pembinaan dan pengembangan pengawas diarahkan untuk memelihara, mempertahankan serta mempertinggi kinerjanya sehingga berdampak pada peningkatan mutu sekolah binaannya. Pembinaan pengawas dimaksudkan sebagai upaya yang terencana dalam memelihara dan meningkatkan kemampuan profesi dan karirnya sehingga mempertinggi kinerjanya sebagai pengawas satuan pendidikan yang professional.

\section{SIMPULAN}

Hasil dari studi ini menghasilkan upaya yang lebih dan maksimal untuk menghilangkan kesenjangan peran pengawas saat ini dalam meningkatkan mutu pendidikan sekolah dasar yaitu : (1) Peranan pengawas harus dijalankan, sehingga gap atau kesenjangan pelaksanan peran yang terjadi selama ini dapat dibangun kembali dengan suatu kebersamaan dan semata-mata tugas Negara yang mulia, yaitu mencerdaskan kehidupan anak bangsa. (2) Intensitas kehadiran pengawas pada sekolah binaan harus lebih ditingkatkan kembali agar 
tidak ada jarak, sehingga keberadaan dan kehadiran pengawas sangat dirindukan sebagai supervisor, advising, monitoring, reporting, coordinating, performing leadership.

\section{DAFTAR PUSTAKA}

Arikunto, S., Suyanto, S., \& Raharja, S. (2006). Pengembangan Kapasitas Kepengawasan Pendidikan di Kota Yogyakarta. Jurnal Penelitian Bappeda Kota Yogyakarta

Anas Rupaedi, 2012. Peranan Pengawas Sekolah Dalam Peningkatan Mutu Pendidikan, UI Press Jakarta

Hoy, W.K., \& Miskel C.G., (2008). Educational Administration: Theory, Research, and Practice. New York : McGraw-Hill.

Joko Budi Santoso, 2011. Peranan Pengawas Sekolah Dalam Ujian Nasional, UII Press, Jakarta.

Nana Sudjana 2011. Supervisi Pendidikan : Konsep dan Aplikasinya Bagi Pengawas Sekolah. (Seri Kepengawasan), Bekasi : Penerbit Binamitra Publishing.

Nana Sudjana. 2006. Standar Mutu Pengawas. Jakarta: Depdiknas

Piet A. Sahertian, (2008). Konsep Dasar \& Teknik Supervisi Pendidikan. Jakarta : Penerbit Rineka Cipta.

Rohmat. Pilar Peningkatan Mutu Pendidikan.Yogyakarta: Cipta Media, 2012

Ruzi Rahmawati. 2012. Program Supervisi Pendidikan dan Program Pembinaan Guru. http://ruzirahmawati.blogspot.co.id/2012/03/program-supervisi-pendidikan- dan.html

Suharsimi Arikunto, (2007). Manajemen Penelitian. Jakarta : Penerbit Rineka Cipta.

Salam, Burhanudin. (1996). Pengantar Pedagogik (dasar-dasar ilmu mendidik). Jakarta : Penerbit Rineka Cipta

Sagala, Syaiful. H. (2008). Budaya dan Reinventing Organisasi Pendidikan. Bandung : Penerbit Alfabeta 